\title{
End-of-life hospital referrals by out-of-hours general practitioners: a retrospective chart study
}

\author{
Maria C De Korte-Verhoef ${ }^{*}$, H Roeline W Pasman ${ }^{1}$, Bart PM Schweitzer ${ }^{2}$, Anneke L Francke ${ }^{1,3}$, \\ Bregje D Onwuteaka-Philipsen ${ }^{1}$ and Luc Deliens ${ }^{1,4}$
}

\begin{abstract}
Background: Many patients are transferred from home to hospital during the final phase of life and the majority die in hospital. The aim of the study is to explore hospital referrals of palliative care patients for whom an out-of-hours general practitioner was called.

Methods: A retrospective descriptive chart study was conducted covering a one-year period (1/Nov/2005 to 1/Nov/2006) in all eight out-of-hours GP co-operatives in the Amsterdam region (Netherlands). All symptoms, sociodemographic and medical characteristics were recorded in 529 charts for palliative care patients. Multivariate logistic regression analysis was performed to identify the variables associated with hospital referrals at the end of life.

Results: In all, 13\% of all palliative care patients for whom an out-of-hours general practitioner was called were referred to hospital. Palliative care patients with cancer (OR 5,1), cardiovascular problems (OR 8,3), digestive problems (OR 2,5) and endocrine, metabolic and nutritional (EMN) problems (OR 2,5) had a significantly higher chance of being referred. Patients receiving professional nursing care $(\mathrm{OR} 0,2)$ and patients for whom their own general practitioner had transferred information to the out-of-hours cooperative $(\mathrm{OR} 0,4)$ had a significantly lower chance of hospital referral. The most frequent reasons for hospital referral, as noted by the out-of-hours general practitioner, were digestive (30\%), EMN (19\%) and respiratory (17\%) problems.

Conclusion: Whilst acknowledging that an out-of-hours hospital referral can be the most desirable option in some situations, this study provides suggestions for avoiding undesirable hospital referrals by out-of-hours general practitioners at the end of life. These include anticipating digestive, EMN, respiratory and cardiovascular symptoms in palliative care patients.
\end{abstract}

Keywords: General Practice, Primary Care, Palliative Care, Out of Hours, Hospital Referral, Cancer, Symptoms

\section{Background}

Many patients are transferred between care settings during the final phase of life [1-4]. In the final months of life, the most frequent trajectory of patients who die a non-sudden death is from home to hospital. The proportion following this trajectory ranges from 36 to $40 \%$ in the final three months of life in the Netherlands and Belgium to $68 \%$ in the final six months of life in Canada. The majority of patients who are transferred from home to hospital later die in hospital [5-7]. Two factors

\footnotetext{
* Correspondence: mc.dekorte-verhoef@vumc.nl

'VU University medical center (VUmc), EMGO Institute for Health and Care Research, Department of Public and Occupational Health \& Expertise Center Palliative Care VUmc, Amsterdam, the Netherlands

Full list of author information is available at the end of the article
}

associated with hospital death are having spent at least one night in a hospital and the number of hospital admissions during the final year of life $[8,9]$.

Hospital transfer, time spent in hospital at the end of life and hospital deaths are mentioned in the literature as poor end-of-life outcome indicators [10-12]. Although some end-of-life hospital transfers are necessary and could benefit the patient, most patients prefer to receive care and die at home, and most families evaluate staying at home as a desirable palliative pathway [13-15].

General practitioners (GPs) are key professionals in providing continuity of care at the end of life $[16,17]$. However, over the last two decades, the 24-hour availability of GPs has changed, with out-of-hours GP co-

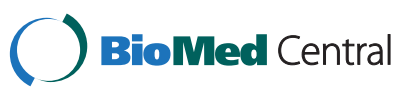


operatives at a greater distance and patients being more likely to receive care from a locum [18,19]; these changes could reduce the continuity of care [20,21]. Proper information transfer from the GP to the outof-hours GP is an essential factor in optimizing continuity of care. In the Netherlands, $82 \%$ of GPs reported that they transferred information about terminally ill patients to out-of-hours GPs [22]. However, various studies of chart analyses of palliative care patients for whom an out-of-hours GP was called have shown that information from the patients' own GP was available only for a minority [22-25].

In a study of patients referred to a palliative care programme, it was found that symptoms other than pain increase the number of transfers to in-patient care at the end of life [2]. However, no details were given about the type of symptoms. Other factors in addition to symptoms have also been found to increase the likelihood of hospital transfer at the end of life. Studies of general practices (not specifically limited to out-of-hours practices) show that age, gender, multiple morbidity, infections, respiratory problems, cardiovascular problems, a palliative treatment goal, GPs' knowledge of patients' wishes about the place of death and palliative treatment by the GP are all related to hospital transfers in the final three months of life $[6,26]$.

The aim of our study was to explore hospital referrals of palliative care patients for whom an out-of-hours GP was called, in recognition of the fact that hospital transfers at the end of life can be undesirable for patients and their families and that the out-of-hours service might be a critical period for these referrals. The research questions were as follows. What is the incidence of hospital referrals of palliative care patients by out-of-hours general practices? What sociodemographic and medical characteristics and what symptoms presented by palliative care patients as noted by an out-of-hours GP are associated with end-of-life hospital referrals? What reasons for referrals from home to hospital are noted by the out-of-hours GP?

\section{Methods}

\section{Design}

A retrospective descriptive chart study was conducted looking at a one-year period ( $1 / \mathrm{Nov} / 2005$ to $1 / \mathrm{Nov} /$ 2006) in all eight out-of-hours GP co-operatives in the Amsterdam region (Netherlands).

\section{Study population and setting}

All 424 GPs in the Amsterdam region with local practices are also required to work shifts as locums for the eight out-of-hours GP cooperatives that serve the 800,000 inhabitants of Amsterdam. Patients who need help during the out-of-hours period can call a special number. Each patient call is noted in an electronic database known as Callmanager.

In the Netherlands, the GP is responsible for patients living at home and in homes for the elderly. Patients living at home have access to professional home care nurses, provided if there is a medical indication, while professional nurses are available 24 hours a day in homes for the elderly.

The Ethics Board of the VU University Medical Center, Amsterdam, was informed about the study, and they decided that the study did not require a formal ethical review.

\section{Patient calls}

The total number of patient calls to the out-of-hours GP co-operatives during the one-year study period was 137,828 . The records of all phone calls were screened electronically. Palliative care patients were identified by means of a search within the text for the words "palliative", "terminal", "cancer", "carcinoma", "inoperable", "opioid" and "fentanyl". The content of the 2304 records identified this way was subsequently examined by a GP with extensive experience in palliative care (BS). He included all contacts in which any mention was made of palliative care needs, palliative medication, remarks about terminal illness etc. This resulted in a list of calls for 553 different palliative care patients. The sensitivity of the search was checked by comparing the electronic search results with a manual search of data for all calls over a one-month period. This did not produce any new calls about palliative care patients and it was therefore decided that the manual search should be stopped [24]. Next, patients were excluded who died just before or during the locum's visit or who were staying in a hospice. This left a total of 529 patients for whom an outof-hours GP co-operative was called (Figure 1).

\section{Recording and analysis of the symptoms and care aspects} One of the authors (BS) analyzed the charts of palliative care patients for whom the out-of-hours GP cooperative was called (for a different paper about GP information transfer). For each patient we had one chart; for patients who had multiple contacts with the GP cooperative, only the final contact chart was included. The author recorded gender, age, type of residence (patient's home or home for the elderly), disease, a single main reason for the encounter, terminal status and hospital referral. Those results have been published elsewhere [24]. This paper is focusing on hospital referrals and this paper's first author (MDK) therefore additionally recorded all the symptoms that were noted in the charts, all medical aspects and the reasons for hospital referral, and discussed this with the third author (BS). The symptoms were noted without interpreting possible mutual or 


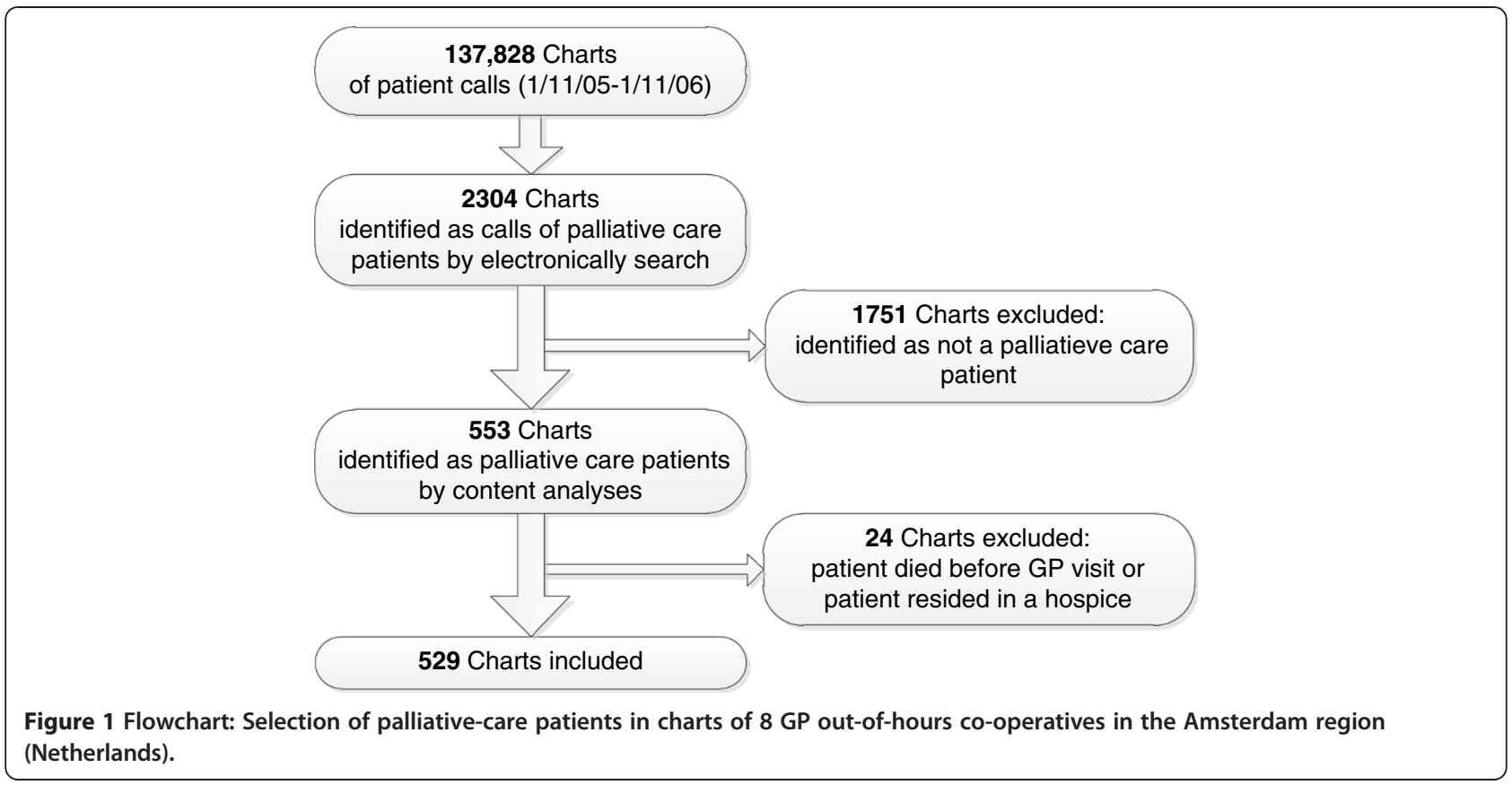

causal relationships. We used the term hospital referral instead of hospital transfer because it is not clear from the charts whether the patient actually went to hospital.

Locums make a short report of the patient calls in a structured 'SOEP' registration system. The subjective reasons for the encounter are noted under $\mathrm{S}$ and the $\mathrm{O}$ contains the locum's observations. The $\mathrm{S}$ and $\mathrm{O}$ categories provided the following variables: symptoms, family aspects, use of professional nursing care, patients' wishes and medical aspects. The E category contains the evaluation of the situation from the locum's perspective and also gives the reason for hospital referral. Finally, the plan - for instance the hospital referral - is noted in the P category. The symptoms were labelled in accordance with the main categories and subcategories of the International Classification of Primary Care (ICPC-2). If they were not described in the ICPC-2, they were classified according to the International Classification of Diseases (ICD10) $[27,28]$. Being terminally ill, the availability of family and receiving professional nursing care were counted as variables if the GP explicitly noted this in the chart. The symptoms presented in the tables are those that were noted for more than $5 \%$ of either of the two groups (patients with hospital referral and patients without hospital referral).

\section{Analysis}

A $T$-test was used to compare the age and number of symptoms of referred patients with that of patients who had no hospital referral. A chi-squared test or Fisher's exact test was used to assess the significance of differences in other sociodemographic and medical characteristics and in symptoms.
Multivariate logistic regression analysis was performed in order to identify the variables associated with hospital referral. First, univariate logistic regression was performed for each of the sociodemographic and medical characteristics (if noted for more than $5 \%$ of patients) and main categories of symptoms individually. All the significant variables $(P<0.05)$ were then entered in a stepwise backward multivariate logistic regression analysis (P-value for removal $>0.05$ ). Because of the large overlap between place of residence (home for the elderly) and receiving professional nursing care, we only included 'receiving professional nursing care' in the multivariate analysis.

\section{Results}

\section{Patient characteristics}

In total, $13 \%$ of all palliative care patients for whom an out-of-hours GP co-operative was called were referred to hospital. Table 1 shows that $53 \%$ of all patients were male, the mean age was $73,84 \%$ lived at home and $76 \%$ had cancer. Patients who were referred to hospital were significantly more likely to live at home (96\% versus $82 \%$ ), to have cancer ( $94 \%$ versus $73 \%$ ) and to be receiving chemotherapy ( $12 \%$ versus $2 \%)$. In addition, patients for whom hospitalization was already planned within three days (10\% versus $1 \%$ ) and patients for whom a hospital specialist had already been contacted ( $9 \%$ versus $1 \%$ ) were significantly more likely to be referred to hospital. Patients were significantly less likely to be referred to hospital if the patient was terminally ill according to the locum (75\% versus 54\%), if the patient was receiving professional nursing care (for the 
Table 1 Sociodemographic and medical characteristics of palliative care patients as noted by an out-of-hours GP $(\mathrm{N}=529)$

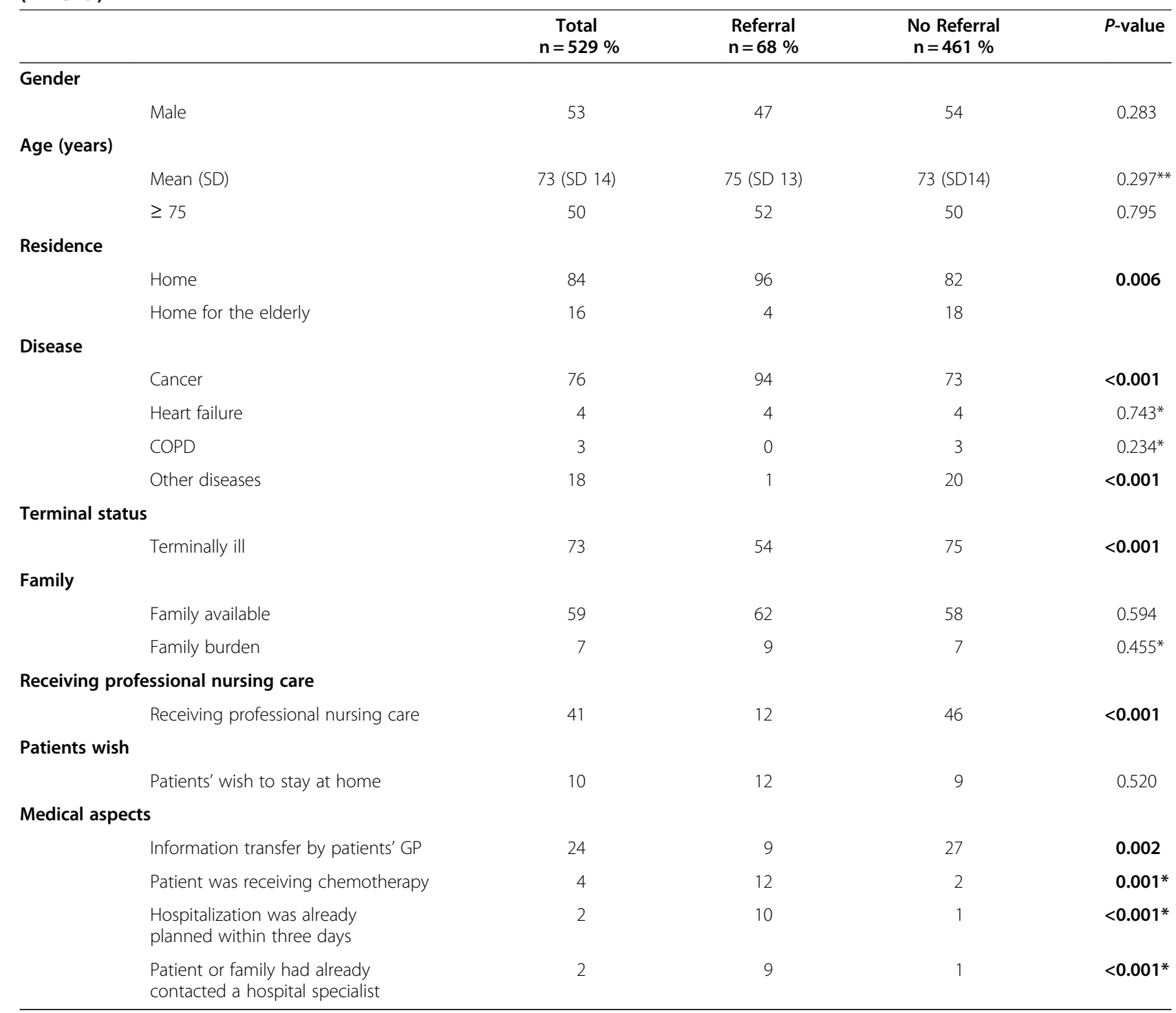

${ }^{*}$ Fisher Exact Test (2-sided).

** $T$-test.

patients not living in a home for elderly: 30\% versus $10 \%)$ or if information was available from the patients' own GP (27\% versus 9\%).

\section{Symptoms}

In total, 39 different symptoms were noted in the SOEP registration system. Pain (42\%), dyspnoea (26\%), agitation/confusion (19\%), loss of appetite (19\%), drowsiness $(14 \%)$ and nausea/vomiting (16\%) were the symptoms most commonly recorded (Table 2). Patients who were referred to hospital had significantly more symptoms (a mean of 3 versus a mean of 2) and were more likely to have digestive problems (53\% versus $26 \%$ ), endocrine, metabolic or nutrition (EMN) problems (46\% versus $22 \%)$ or cardiovascular problems (13\% versus $4 \%)$ than patients who were not referred. Looking in greater detail, the patients referred were more likely to have problems with nausea/vomiting (41\% versus $12 \%$ ), loss of appetite (35\% versus $17 \%)$, dehydration (16\% versus $3 \%$ ), cachexia (12\% versus $5 \%$ ), pulmonary or deep venous thrombosis ( $7 \%$ versus $1 \%$ ) and ileus ( $7 \%$ versus $2 \%$ ).

\section{Associations with hospital referral}

Cancer, terminal illness, receiving nursing care, information transfer, digestive problems, EMN problems, cardiovascular problems and patients with more than two 
Table 2 Symptoms as noted by an out-of-hours GP $(\mathrm{N}=529)$ (the $\mathrm{S}$ and $\mathrm{O}$ in the SOEP registration)

\begin{tabular}{|c|c|c|c|c|}
\hline Main ICPC category & \multirow{2}{*}{$\begin{array}{c}\text { Total } \\
n=529 \%\end{array}$} & \multirow{2}{*}{$\begin{array}{l}\text { Referral } \\
n=68 \%\end{array}$} & \multirow{2}{*}{$\begin{array}{c}\text { No Referral } \\
n=461 \%\end{array}$} & \multirow[t]{2}{*}{$P$-value } \\
\hline Symptom & & & & \\
\hline General & 48 & 52 & 48 & 0.564 \\
\hline Pain & 42 & 46 & 41 & 0.495 \\
\hline Fever $\geq 38$ & 5 & 6 & 5 & $0.762^{*}$ \\
\hline Other & 3 & 4 & 3 & $0.446^{*}$ \\
\hline Digestive & 30 & 53 & 26 & $<0.001$ \\
\hline Vomiting/ nausea & 16 & 41 & 12 & $<0.001$ \\
\hline Swallowing problems & 8 & 6 & 8 & 0.575 \\
\hline Diarrhoea & 3 & 6 & 3 & $0.137^{*}$ \\
\hline lleus & 3 & 7 & 2 & $0.017^{*}$ \\
\hline Ascites & 2 & 6 & 2 & $0.056^{*}$ \\
\hline Other & 6 & 4 & 6 & $0.785^{*}$ \\
\hline Respiratory & 26 & 31 & 25 & 0.335 \\
\hline Dyspnoea & 26 & 31 & 25 & 0.296 \\
\hline Other & 1 & 2 & 1 & $0.564^{*}$ \\
\hline Endocrine, metabolic or nutritional & 25 & 46 & 22 & $<0.001$ \\
\hline Loss of appetite & 19 & 35 & 17 & $<0.001$ \\
\hline Cachexia & 6 & 12 & 5 & $0.042^{*}$ \\
\hline Dehydration & 4 & 16 & 3 & $<0.001^{*}$ \\
\hline Other & 2 & 3 & 2 & $0.625^{*}$ \\
\hline Psychological & 24 & 19 & 24 & 0.444 \\
\hline Agitation and confusion & 19 & 15 & 19 & 0.385 \\
\hline Other & 8 & 4 & 9 & 0.249 \\
\hline Neurological & 16 & 9 & 17 & 0.088 \\
\hline Drowsiness & 15 & 7 & 16 & 0.055 \\
\hline Other & 1 & 3 & 1 & $0.174^{*}$ \\
\hline Urological & 8 & 9 & 8 & 0.812 \\
\hline Cardiovascular & 5 & 13 & 4 & 0.001 \\
\hline Pulmonary or deep venous embolism & 2 & 7 & 1 & $0.005^{*}$ \\
\hline Other & 2 & 6 & 2 & $0.056^{*}$ \\
\hline Skin problems & 5 & 7 & 5 & 0.387 \\
\hline Number of Symptoms (mean, SD) & 2.1 (SD 1.4) & 3,0 (SD 1.6) & 2,0 (SD 1.3) & $0.038^{* *}$ \\
\hline Patients with $>2$ symptoms & 32 & 56 & 28 & $<0.001$ \\
\hline
\end{tabular}

*Fisher Exact Test (2-sided).

** $T$-test.

symptoms were significantly related to out-of-hours hospital referral in the univariate logistic regression analysis $(P<0.05)$ and were therefore included in the multivariate logistic regression analysis. Six variables remained significant (Table 3). Patients with cardiovascular problems (OR 8.3), cancer (OR 5.1), digestive problems (OR 2.5) and EMN problems (OR 2.5) were more likely to be referred to hospital. Patients who received professional nursing care (OR 0.2) and for whom their own GP had transferred information (OR 0.4 ) were less likely to be referred to hospital.

\section{Reasons for hospital referral}

Twenty different symptoms and two other problems were noted as a reason for hospital referral from the perspective of the locum (Table 4). Digestive problems (31\%), EMN problems (19\%) and respiratory problems (18\%) were the most common. At a more detailed level, 
Table 3 Association with end-of-life hospital referral*

\begin{tabular}{ll}
\hline Cancer & OR $\mathbf{( 9 5 \% ~ C l )}$ \\
Cardiovascular problems & $5.1(1.7-15.8)$ \\
Digestive problems & $8.3(2.9-24,0)$ \\
Endocrine, metabolic, and nutritional problems & $2.5(1.4-4.6)$ \\
Receiving professional nursing care & $2.5(1.4-4.5)$ \\
Information transfer by GP & $0.2(0.1-0.5)$ \\
\hline
\end{tabular}

*Stepwise backward multivariate logistic regression analysis. The model demonstrated good calibration performance according to the Hosmer-Lemeshow goodness-of-fit test $(P=0.97)$ and a discriminatory ability of the area under the curve (AUC) of 0.83 .

Table 4 Reasons for hospital referral as noted by the out-of-hours GP (the $E$ in the SOEP registration $N=68$ )

\begin{tabular}{|c|c|c|c|}
\hline & & $\mathbf{N}$ & $\%$ \\
\hline \multirow[t]{6}{*}{ Digestive } & & 21 & 30.9 \\
\hline & Vomiting (incl. haematemesis) & 11 & 16.2 \\
\hline & lleus & 4 & 5.9 \\
\hline & Ascites & 3 & 4.4 \\
\hline & Rectal bleeding & 2 & 2.9 \\
\hline & Peritonitis & 1 & 1.5 \\
\hline \multicolumn{2}{|c|}{ Endocrine, metabolic and nutritional } & 13 & 19.1 \\
\hline & Dehydration & 11 & 16.2 \\
\hline & Hyperglycaemia & 2 & 2.9 \\
\hline \multirow[t]{3}{*}{ Respiratory } & & 12 & 17.6 \\
\hline & Pneumonia/pleuritis & 9 & 13.2 \\
\hline & Dyspnoea & 3 & 4.4 \\
\hline \multirow[t]{4}{*}{ Cardiovasc } & & 8 & 11.8 \\
\hline & Cardiac & 4 & 5.9 \\
\hline & Deep venous thrombosis (feet) & 3 & 4.4 \\
\hline & Pulmonary embolism & 1 & 1.5 \\
\hline \multirow[t]{4}{*}{ General } & & 7 & 10.3 \\
\hline & Pain & 5 & 7.4 \\
\hline & Weakness & 1 & 1.5 \\
\hline & Fever & 1 & 1.5 \\
\hline \multicolumn{2}{|c|}{ Other symptoms } & 14 & 20.6 \\
\hline & Epilepsy & 6 & 8.8 \\
\hline & Anuria & 4 & 5.9 \\
\hline & Confusion/delirium & 3 & 4.4 \\
\hline & Fracture & 1 & 1.5 \\
\hline \multicolumn{4}{|c|}{ Other aspects } \\
\hline & Family burden or no family & 6 & 8.8 \\
\hline & Diagnosis in the hospital & 1 & 1.5 \\
\hline
\end{tabular}

vomiting (16\%), dehydration (16\%) and pneumonia/ pleuritis $(13 \%)$ were the reasons most often given for hospital referral. Two or three symptoms were mentioned for eleven patients and the family burden was mentioned for three patients.

\section{Discussion}

Examining 529 records of palliative care patients from out-of-hours GP co-operatives in the Amsterdam region, we found that $13 \%$ of palliative care patients were referred to a hospital. Palliative care patients with cancer, cardiovascular problems, digestive problems and endocrine, metabolic and nutritional (EMN) problems had a significantly higher chance of being referred after the out-of-hours consultation. Patients receiving professional nursing care and patients for whom their own GP had transferred information to the out-of-hours co-operative had a significantly lower chance of being referred after calling an out-of-hours GP. The reasons most commonly given for hospital referral were digestive problems, EMN problems and respiratory problems. The most common digestive problem was vomiting and the EMN problem noted most often was dehydration.

\section{Sociodemographic and medical characteristics}

The multivariate analyses showed that palliative care patients had a lower chance of hospital referral in the out-of-hours period if they were receiving nursing care. Other studies have also found that patients receiving professional nursing care at the end of life are more likely to stay at home $[29,30]$. It is reasonable to assume that the nurse will in many cases know the patient's situation and the care options at home better than a locum and will consequently be able to propose alternative 'solutions' to hospitalization. It therefore seems that nurses may considered as one of the 'gatekeepers' of outof-hours hospitalization of palliative care patients. In addition to nursing involvement, it was also found that patients were less likely to be referred to hospital if their GP had transferred information to the locum. However, we also found that information from the patients' own GP was only available for a minority of patients during the out-of-hours period. This lack of information transfer has also been noted in other studies looking at outof-hours practices $[22,23,25]$.

\section{Symptoms}

Although $42 \%$ of the patients in this study were found to be in pain, this was often not the reason noted for outof-hours hospital referrals. Symptoms such as digestive, EMN and respiratory problems were noted down more frequently as reason for referral. This suggests that outof-hours GPs may be better at handling pain in palliative care patients than other symptoms. 
As in our study, studies concerning out-of-hours care but not specifically focusing on palliative care patients also found that digestive problems are frequently recorded as a symptom [30,31]. We found digestive problems to be positively related to hospital referrals as well. About half of the referred patients in our study had digestive problems and $78 \%$ of these patients had problems with nausea and/or vomiting. Nausea/vomiting can have several causes, such as hypercalcaemia, obstipation, ascites, ileus or intracranial pressure [32]. The complexity of diagnosing or treating this might be a reason for hospital referral.

EMN problems were not found to be noted frequently in other studies [30,31], but in our study it was noted as a problem for $25 \%$ of the patients. EMN problems were also found to be significantly related to hospital referrals in our study. In the EMN category, $83 \%$ of the problems were caused by nutritional problems (loss of appetite, dehydration and cachexia). It is neither immediately apparent why an out-of-hours GP co-operative might be called for nutritional problems nor why out-of-hours GPs might consider this to be an acute reason for hospital referral.

\section{Strengths and limitations of the study}

The strength of the study is the detailed information about sociodemographic and medical characteristics and symptoms of patients for whom an out-of-hours GP was called. A limitation of the study is that data was collected six years ago; however, there is no indication that GP services have changed substantially in the intervening years. Another limitation of the study is that problems were not measured systematically, for instance using a scoring list. Instead, the study used the reported problems as noted in the charts, which means that patients could have had additional problems. However, it is assumed that the problems noted were those causing the most distress. Furthermore, in our study it is possible that not all palliative care patients were detected by the electronic search strategy, although it should be noted that a manual search of a subset of the data did not uncover new patients. Additionally, it is not known whether the referred patients were indeed transferred to hospital after referral. Finally, we do not know if the hospital referrals found in our study could have been avoided or were undesirable.

\section{Conclusion}

The results of this study provide detailed information about associations with hospital referrals, and the reasons for hospital referral outside standard hours. Whilst acknowledging that hospital referral can be the most desirable option in some situations, this study provides suggestions for avoiding undesirable hospital referrals at the end of life. Since it is not known how many of the hospital referrals were potentially avoidable and/or undesirable, further research should be done in this area. In order to anticipate potentially undesirable hospital transfers in out-of-hours periods, patients' GPs could decide to provide information to out-of-hours GPs at an early stage, arrange for a nurse at home and be alert to digestive, nutritional and cardiovascular symptoms.

\section{Competing interest}

The authors have declared that they have no competing interests.

\section{Authors' contributions}

MDK performed the draft and the statistical analyses of this paper together with HP. BS and MDK analyzed the charts of palliative care patients. HP and LD initiated the study and obtained the funding. HP, BOP, AF and LD supervised the project. All authors read, revised and approved the final manuscript.

\section{Acknowledgements}

This study is funded by ZonMw, the Netherlands Organization for Health Research and Development, AGIS Health Insurance Company and the Comprehensive Cancer Centre (IKA) in Amsterdam. We would like to thank Martijn Heymans of the VUmc for his advice on the statistics.

\section{Author details}

${ }^{1} V U$ University medical center (VUmc), EMGO Institute for Health and Care Research, Department of Public and Occupational Health \& Expertise Center Palliative Care VUmc, Amsterdam, the Netherlands. ${ }^{2}$ VU University medical center, EMGO Institute for Health and Care Research, Department of General Practice, Amsterdam, the Netherlands. ${ }^{3}$ NIVEL, Netherlands Institute for Health Services Research, Utrecht, the Netherlands. ${ }^{4}$ Ghent University \& Vrije Universiteit Brussel, End-of-life Care Research Group, Brussels, Belgium.

Received: 2 April 2012 Accepted: 6 August 2012

Published: 22 August 2012

\section{References}

1. Burge FI, Lawson B, Critchley P, Maxwell D: Transitions in care during the end of life: changes experienced following enrolment in a comprehensive palliative care program. BMC Palliat Care 2005, 4:3.

2. Lawson B, Burge Fl, Critchley P, McIntyre P: Factors associated with multiple transitions in care during the end of life following enrollment in a comprehensive palliative care program. BMC Palliat Care 2006, 5:4.

3. Sharma G, Freeman J, Zhang D, Goodwin JS: Continuity of care and intensive care unit use at the end of life. Arch Intern Med 2009, 169:81-86.

4. Wilson DM, Hewitt JA, Thomas R, Mohankumar D, Kovacs BK: Age-Based Differences in Care Setting Transitions over the Last Year of Life. Curr Gerontol Geriatr Res 2011, 201(1):101276.

5. Van den Block L, Deschepper R, Drieskens K, Bauwens S, Bilsen J, Bossuyt N, Deliens L: Hospitalisations at the end of life: using a sentinel surveillance network to study hospital use and associated patient, disease and healthcare factors. BMC Health Serv Res 2007, 7:69.

6. Abarshi E, Echteld M, Van den Block L, Donker G, Deliens L, OnwuteakaPhilipsen B: Transitions between care settings at the end of life in the Netherlands: results from a nationwide study. Palliat Med 2010, 24:166-174.

7. Barbera L, Paszat L, Qiu F: End-of-life care in lung cancer patients in Ontario: aggressiveness of care in the population and a description of hospital admissions. J Pain Symptom Manage 2008, 35:267-274.

8. Cardenas-Turanzas M, Torres-Vigil I, Tovalin-Ahumada H, Nates JL: Hospital versus home death: results from the Mexican Health and Aging Study. J Pain Symptom Manage 2011, 41:880-892.

9. Alonso-Babarro A, Bruera E, Varela-Cerdeira M, Boya-Cristia MJ, Madero R, Torres-Vigil I, De Castro J, Gonzalez-Baron M: Can this patient be discharged home? Factors associated with at-home death among patients with cancer. J Clin Oncol 2011, 29:1159-1167. 
10. Ahlner-Elmqvist M, Jordhoy MS, Jannert M, Fayers $P$, Kaasa S: Place of death: hospital-based advanced home care versus conventional care. A prospective study in palliative cancer care. Palliat Med 2004, 18:585-593.

11. Jordhoy MS, Fayers P, Saltnes T, Ahlner-Elmqvist M, Jannert M, Kaasa S: A palliative care intervention and death at home: a cluster randomised trial. Lancet 2000, 356:888-893.

12. Gozalo P, Teno JM, Mitchell SL, Skinner J, Bynum J, Tyler D, Mor V: End-oflife transitions among nursing home residents with cognitive issues. $N$ Engl J Med 2011, 365:1212-1221.

13. Beccaro M, Costantini M, Giorgi RP, Miccinesi G, Grimaldi M, Bruzzi P: Actual and preferred place of death of cancer patients. Results from the Italian survey of the dying of cancer (ISDOC). J Epidemiol Community Health 2006, 60:412-416.

14. Higginson IJ, Sen-Gupta GJ: Place of care in advanced cancer: a qualitative systematic literature review of patient preferences. J Palliat Med 2000, 3:287-300.

15. Neergaard MA, Vedsted P, Olesen F, Sokolowski I, Jensen AB, Sondergaard J: Associations between successful palliative trajectories, place of death and GP involvement. Scand J Prim Health Care 2010, 28:138-145.

16. Borgsteede SD, Graafland-Riedstra C, Deliens L, Francke AL, van Eijk JT, Willems DL: Good end-of-life care according to patients and their GPs. Br $J$ Gen Pract 2006, 56:20-26.

17. Michiels E, Deschepper R, Van Der Kelen G, Bernheim JL, Mortier F, Vander Stichele R, Deliens $L$ : The role of general practitioners in continuity of care at the end of life: a qualitative study of terminally ill patients and their next of kin. Palliat Med 2007, 21:409-415.

18. Grol R, Giesen P, van Uden C: After-hours care in the United Kingdom, Denmark, and the Netherlands: new models. Health Aff (Millwood) 2006, 25:1733-1737.

19. Leibowitz R, Day S, Dunt D: A systematic review of the effect of different models of after-hours primary medical care services on clinical outcome, medical workload, and patient and GP satisfaction. Fam Pract 2003, 20:311-317.

20. Huibers L, Giesen P, Wensing M, Grol R: Out-of-hours care in western countries: assessment of different organizational models. BMC Health Serv Res 2009, 9:105.

21. Schweitzer B, Blankenstein N, Deliens L, van der Horst H: Out-of-hours palliative care provided by GP co-operatives in the Netherlands: A focus group study. Eur J Gen Pract 2011, 17:160-166.

22. Schweitzer B, Blankenstein N, Willekens M, Terpstra E, Giesen P, Deliens L: GPs' views on transfer of information about terminally ill patients to the out-of-hours co-operative. BMC Palliat Care 2009, 8:19.

23. De Bock GH, Van Kampen I, Van der Goot JH, Hamstra M, Dekker JH, Schuit KW, van der Meer K: Transfer of information on palliative home care during the out-of-hours period. Fam Pract 2011, 28:280-286.

24. Schweitzer BP, Blankenstein N, Deliens $L$, van der Horst H: Out-of-hours palliative care provided by GP co-operatives: availability, content and effect of transferred information. BMC Palliat Care 2009, 8:17.

25. Burt J, Barclay S, Marshall N, Shipman C, Stimson A, Young J: Continuity within primary palliative care: an audit of general practice out-of-hours co-operatives. J Public Health (Oxf) 2004, 26:275-276.

26. Van den Block L, Deschepper R, Bilsen J, Van CV, Deliens L: Transitions between care settings at the end of life in Belgium. JAMA 2007, 298:1638-1639.

27. WONCA International Classification Committee: ICPC-2-R:International classification of primary care. 2nd edition. Oxford: OxfordUniversity Press; 2005.

28. WHO. http://apps.who.int/classifications/apps/icd/icd10online/ (visited march 21, 2012)

29. Gomes B, Higginson IJ: Factors influencing death at home in terminally ill patients with cancer: systematic review. BMJ 2006, 332:515-521.

30. Seow H, Barbera L, Sutradhar R, Howell D, Dudgeon D, Atzema C, Liu Y, Husain A, Sussman J, Earle C: Trajectory of performance status and symptom scores for patients with cancer during the last six months of life. J Clin Oncol 2011, 29:1151-1158.
31. Huber CA, Rosemann T, Zoller M, Eichler K, Senn O: Out-of-hours demand in primary care: frequency, mode of contact and reasons for encounter in Switzerland. J Eval Clin Pract 2011, 17:174-179.

32. Davis MP, Walsh D: Treatment of nausea and vomiting in advanced cancer. Support Care Cancer 2000, 8:444-452.

doi:10.1186/1471-2296-13-89

Cite this article as: De Korte-Verhoef et al: End-of-life hospital referrals by out-of-hours general practitioners: a retrospective chart study. BMC Family Practice 2012 13:89.

\section{Submit your next manuscript to BioMed Central and take full advantage of:}

- Convenient online submission

- Thorough peer review

- No space constraints or color figure charges

- Immediate publication on acceptance

- Inclusion in PubMed, CAS, Scopus and Google Scholar

- Research which is freely available for redistribution

Submit your manuscript at www.biomedcentral.com/submit
Ciomed Central 